\title{
VIOLÊNCIA NAS RELAÇÕES JUVENIS DE INTIMIDADE: UMA REVISÃO DA TEORIA, DA INVESTIGAÇÃO E DA PRÁTICA
}

\author{
Sónia Caridade ${ }^{1}$ \\ Carla Machado ${ }^{2}$
}

[Enviado a 26-09-2012. Aceite a 21-11-2012]

\begin{abstract}
Resumo: A investigação sobre a violência nas relações de intimidade começou por privilegiar o casamento enquanto principal objeto de estudo, negligenciando-se as relações de namoro e ocasionais e as relações homossexuais. Não obstante este tardio interesse pelo estudo da violência nas relações íntimas juvenis, temos assistido, progressivamente, a uma multiplicação dos estudos nesta área. É neste contexto que surge o projeto "Violência nas relações juvenis de intimidade" cujo principal objetivo era o de reduzir a lacuna existente no conhecimento acerca da extensão e gravidade deste fenómeno. Neste artigo, para além de procedermos a uma descrição geral e alargada do estado atual da investigação e do conhecimento teórico produzido acerca da violência ocorrida nas relações de intimidade juvenil, quer no contexto internacional, quer nacional, apresentamos o referido projeto de investigação, analisando e discutindo os seus resultados e implicações dos mesmos para a prática preventiva.
\end{abstract}

Palavras-chave: Violência Íntima, Relações Juvenis, Prevenção, Atitudes.

Violence in juvenile dating relationships: An overview of theory, research and practice (Abstract): Research on violence in intimate relationships began to privilege marriage as the main object of study, neglecting dating relationships and occasional juvenile and homosexual relations. Despite this delayed interest in the study of juvenile violence in intimate relationships, we have witnessed a progressive proliferation of studies in this area. It is in this context that emerges the pro-

\footnotetext{
${ }^{1}$ Faculdade de Ciências Humanas e Sociais, Universidade Fernando Pessoa. Autor para correspondência: Sónia Caridade, Universidade Fernando Pessoa, Praça 9 de abril, 349, 4249-004, Porto - Portugal email: soniac@ufp.edu.pt

2 Escola de Psicologia, Universidade do Minho
} 
ject "Violence in juvenile dating relationships", whose main goal was to reduce the gap of knowledge about the extent and severity of this phenomenon. In this article, we proceed to a broad overview of the national and international research and the theoretical knowledge produced on this subject, describe the research project, analyze and discuss the results as well as their implications for prevention.

Keywords: Intimate Violence, Juvenile Relationships, Prevention, Attitudes.

\section{Introdução}

A investigação científica sobre o tema da violência nas relações de intimidade começou por privilegiar, durante cerca de duas décadas, o casamento/união de facto enquanto principal objeto de estudo, negligenciando-se outros contextos relacionais, como as relações de namoro e ocasionais ou mesmo as relações homossexuais. As dificuldades inerentes à própria definição do conceito de violência e sua operacionalização, o difícil acesso dos investigadores à população juvenil (e.g., necessidade de autorização dos pais) e a inexistência de um estatuto legal, autónomo, alusivo à violência fora dos contextos maritais (e.g., situação que condiciona quer a sinalização, quer o acesso desta população aos serviços de apoio formais) constituem alguns impedimentos à visibilidade social desta problemática e que, durante anos, contribuíram para a sua ocultação, comprometendo, deste modo, a produção do conhecimento científico neste âmbito.

Até aos anos oitenta, a extensão e gravidade deste fenómeno eram desconhecidas, e só em 1981 surge um estudo pioneiro na área da violência na intimidade juvenil, desenvolvido por Makepeace. Este estudo veio, assim, revelar que um em cada cinco estudantes universitários era afetado por este problema e que $61 \%$ da amostra revelava conhecer jovens com experiências de namoro abusivas. Desde então assistimos a um aumento dos estudos de prevalência e das dinâmicas violentas subjacentes a este tipo de relacionamentos.

Na origem desta extensão da investigação a outros contextos relacionais esteve a administração de inquéritos de vitimação ou inquéritos sobre violência auto-relatada a largas amostras populacionais, tendo-se constatado que a violência não era exclusiva das relações maritais, mas que poderia iniciar-se em faixas etárias mais precoces. Os dados provenientes de diversos estudos sugerem que a violência sofrida e/ou praticada por adolescentes poderá situar-se entre os $13 \%$ e os $42 \%$ (e.g., Luthra \& Gidycz, 2006; Perry $\&$ Fromuth, 2005). Um estudo mais recente (Miller, 2011) apurou que um em cada quatro estudantes universitários estava envolvido em relações íntimas violentas, tendo experienciado pelo menos um ato abusivo. Por sua vez, 
uma revisão da produção científica internacional nesta área encontrou taxas de prevalência (ofensores ou vítimas) que poderão ir desde os 12,1\% (Henton, Cate, Roval, Lloyd, \& Christopher, 1983) até aos 72,4\% (Aldrighi, 2004). Apesar desta grande disparidade e variabilidade registada nos indicadores de prevalência da violência, os quais têm sido atribuídos maioritariamente às opções metodológicas e concetuais empregues pelos diversos estudos (e.g., ausência de uma definição clara de violência, o período temporal considerado, a natureza da medida utilizada, o viés da amostragem) (cf. Caridade, 2011), é consensual que a violência nas relações de intimidade entre os adolescentes e jovens adultos encerra um problema social relevante e merecedor de atenção em si mesmo. A análise dos diferentes estudos epidemiológicos realizados nesta área comprova ainda que a violência nas relações de intimidade é um fenómeno transversal às mais diversas culturas e grupos étnicos (Caridade, 2011).

Ao longo deste artigo, procedemos a uma descrição geral e alargada do estado atual da investigação e do conhecimento teórico produzido acerca da violência ocorrida nas relações de intimidade juvenil, quer no contexto internacional, quer nacional. Na descrição da realidade portuguesa, daremos particular destaque a um projeto de investigação intitulado "Violência nas relações juvenis de intimidade" (com a referência: PTDC/PSI/65852/2006), desenvolvido em território português e financiado pela Fundação para a Ciência e Tecnologia, sob a coordenação da segunda autora deste artigo, procurando-se apresentar e discutir alguns dos resultados e implicações dos mesmos para a prática preventiva neste domínio. A concluir, procuraremos igualmente debater os novos desafios para a investigação e intervenção futuras nesta área.

\section{Perspetivas e modelos teóricos de compreensão da violência íntima juvenil}

Pese embora a considerável investigação já produzida no domínio da violência nas relações íntimas juvenis, verifica-se um menor investimento no desenvolvimento de abordagens teóricas explicativas da violência ocorrida neste contexto relacional específico. Ainda que a literatura tenha vindo a identificar um vasto número de variáveis que poderão predispor os jovens à violência (e.g., Follingstad, Bradley, Laughlin, \& Burke, 1999; Hickman, Jaycox, \& Aronoff, 2004), com particular destaque para a vitimação prévia na infância, seja por violência direta ou indireta (exposição à violência interparental), as atitudes legitimadoras da violência, o consumo de álcool e outros fatores intra e interpessoais (e.g., baixa autoestima, depressão, reduzidas competências comunicacionais), apenas um número muito reduzido de 
investigadores procurou conceptualizar o problema da violência nas relações de intimidade juvenil.

$\mathrm{Na}$ verdade, e não raras vezes, as abordagens teóricas que são evocadas para compreender este fenómeno são as que foram elaboradas para explicar a violência noutros contextos relacionais e que envolvem relações entre adultos (e.g., conjugalidade) com dinâmicas e contingências relacionais distintas (e.g., a eventual dependência económica, a existência de filhos). Adicionalmente, as parcas abordagens teóricas que surgem neste domínio não foram alvo de comprovação empírica (e.g., Riggs \& O'Leary, 1996) e não são utilizadas na fundamentação dos programas de prevenção, limitando deste modo a eficácia dos esforços preventivos e da intervenção em geral nesta área.

Uma revisão da literatura sobre as abordagens explicativas da violência nas relações íntimas em geral (Dias, 2012) defende a existência de um percurso evolutivo neste domínio, partindo-se das abordagens mais individuais (teorias intra-individuais), passando pelas dinâmicas e sistémicas (teorias diádicas-familiares) e culminando numa perspetiva mais abrangente que procura a contextualização cultural do fenómeno (abordagens socioculturais). Efetivamente, são múltiplas as correntes explicativas da violência íntima que têm procurado deixar o seu contributo na elucidação deste fenómeno, mas as quais se têm revelado insuficientes para explicar a violência íntima juvenil. Estas diferentes abordagens poderão divergir consoante o contexto social enfatizado (e.g., família, pares) e a ênfase dada a certas variáveis estruturais, situacionais, culturais e psicológicas (Mahlstedt \& Welsh, 2005). Não obstante, e ainda que no debate acerca dos fatores de risco se procure discutir a importância da dimensão cultural da violência, é verdade que predomina, essencialmente, literatura sobre os fatores mais centrados na família e no sujeito individual. Passamos, de seguida, a apresentar, por ordem da sua emergência histórica, as principais perspetivas e modelos teóricos mais utilizados na explicação da violência ocorrida nas relações íntimas juvenis, procedendo-se a uma revisão crítica dos mesmos.

As perspetivas intra-individuais destacam-se por terem sido as primeiras explicações teóricas a dar o seu contributo na explicação da violência íntima em geral. De uma forma muito genérica, estas abordagens para além de procurarem compreender as ações dos agressores a partir das suas características biológicas e psicológicas, procuram igualmente descrever a personalidade das vítimas e a sua vulnerabilidade psicológica para a ocorrência do abuso (cf. Hydén, 1995). Refira-se, aliás, que alguns autores (Rensetti, 1994 cit. in Sharpe \& Taylor, 1999) preconizam mesmo que a compreensão da violência íntima deve envolver a análise das diferenças ao nível das variáveis individuais. Estas perspetivas centram-se, fundamentalmente, nas experiências precoces de violência dos indivíduos (e.g., exposição à violência interparental, experienciação de abuso sexual na infância) aliada à presença de 
determinados fatores situacionais (e.g., consumo de álcool, conflitos relacionais). A violência nas relações íntimas juvenis surge, muitas vezes, percebida como sendo consequência das atitudes individuais de cada um, da dificuldade que os jovens possuem em resolver os conflitos relacionais, em que os ciúmes e a dificuldade em controlar a raiva surgem como sendo as principais causas da violência (e.g., Sugarman \& Hotaling, 1989).

Ainda que um vasto corpo teórico privilegie o recurso a fatores individuais na explicação da violência na intimidade (cf., Ismail, Berman, \& Ward-Griffin, 2007), ideia igualmente difundida no senso comum, estas explicações intra-individuais têm-se revelado insuficientes e, por vezes, inadequadas na compreensão do problema. Do nosso ponto de vista, privilegiar as explicações internas, em detrimento de outras abordagens, poderá contribuir para uma individualização do problema, escamoteando outros factores (e.g., socioculturais) que poderão desempenhar um contributo igualmente importante na explicação deste fenómeno. Além disso, e pensando numa lógica preventiva, uma ênfase nesta conceção individualista significaria que a sua erradicação passaria apenas por uma questão de tratamento clínico dos agressores e das vítimas, em detrimento de uma intervenção mais social (Matos, 2002) e de carácter mais comunitário.

Dentro das perspetivas diádicas-familiares, a noção de aprendizagem social inerente à teoria intergeracional da violência é a que tem merecido mais destaque pelos investigadores da área que têm procurado explicar este fenómeno (Hines \& Saudino, 2002). Esta abordagem sustenta que o comportamento de cada indivíduo é determinado pelo ambiente em que este se insere, particularmente pelos elementos da sua família, mediante mecanismos de observação, reforço, modelagem ou coacção (Foo \& Margolin, 1995). Nesta linha de pensamento, uma criança que tenha sido exposta à violência interparental ou que tenha sofrido maus tratos na infância apresentará maior probabilidade de vir a reproduzir estes comportamentos e/ou de evidenciar uma maior tolerância face a este tipo de práticas abusivas. A vitimação direta ou indireta (exposição ao conflito interparental) poderá contribuir para a aceitação deste tipo de práticas e, deste modo, a violência ser interpretada como uma forma adequada de resolução dos conflitos (Riggs \& O'Leary, 1996). O recurso à violência pelos jovens expostos ao conflito familiar tem sido ainda atribuído ao facto de estes associarem à violência interpessoal mais funcionalidades positivas do que consequências negativas e, consequentemente, desenvolverem expectativas positivas face ao comportamento violento (Foshee, Bauman, \& Linder, 1999). Por sua vez, outros autores defendem (e.g., Dutton, 1999) que a modelagem não se processa apenas ao nível das atitudes e comportamentos, mas inclui também a modelagem de certas características de personalidade que sustentam o abuso íntimo (e.g., tendência para externalizar a responsabilidade, emoções desproporcionais face à rejei- 
ção/abandono). Por outro lado, a modelagem de crenças legitimadoras da violência poderá não advir apenas do seu testemunho direto ou indireto, mas também do papel da família enquanto agente de transmissão de certos valores ideológicos e sociais (e.g., atitudes e crenças sobre os papéis de género e a violência) promotores de condutas violentas (Gelles, 1997).

Em suma, a noção de aprendizagem social da violência e o seu potencial em termos da transmissão intergeracional proporciona também contributos fundamentais neste âmbito, ao alertar para a importância dos contextos precoces de socialização familiar e da influência dos pares no comportamento agressivo. Contudo, há ainda situações para as quais este paradigma não nos proporciona explicações suficientemente satisfatórias. De forma mais específica, referimo-nos às situações em que os jovens, ainda que tenham sido confrontados com o drama da violência familiar, não assumem comportamentos violentos nas suas relações de intimidade, ou ainda, os casos em que não tendo os jovens experienciado qualquer tipo de violência na família, adoptam estratégias maltratantes para com o(a) parceiro(a) amoroso(a). Tal tem conduzido à emergência de algumas questões relevantes que deverão continuar a motivar a investigação neste domínio (cf. Jackson, 1999): Como explicar e a que fatores atribuir o facto de as pessoas inseridas em contextos violentos se mostrarem adaptadas e funcionais, não registando experiências de vitimação elou perpetração de abuso íntimo? Qual é a real motivação para o recurso à violência em pessoas oriundas de contextos violentos? Qual é de facto a real influência do agressor (seja masculino ou feminino) da familia de origem sobre a agressão feminina e masculina nas relações intimas juvenis?

A ausência de evidências mais consistentes no domínio da transmissão intergeracional da violência tem sido atribuída à existência de problemas metodológicos, tais como o facto de a maioria da investigação empírica neste âmbito se basear em relatos retrospetivos das experiências de violência sofridas na infância, sendo esparsos os estudos de natureza prospetiva (Lichter \& McCloskey, 2004). Adicionalmente, o facto de muitos estudos recorrerem a amostras de conveniência poderá influenciar os resultados, na medida em que as experiências precoces de violência, as atitudes e as motivações destes participantes são, muitas vezes, sujeitos a enviesamentos (e.g., a grande maioria das amostras contém poucos participantes com características antissociais) (Simons, Lin, \& Gordon, 1998).

Outros contributos importantes na explicação do comportamento violento íntimo derivam de modelos importados da área da criminologia. Em linhas gerais, os estudos (e.g., Simons et al., 1998) desenvolvidos neste domínio conceptualizam a violência íntima como a expressão de um padrão de conduta antissocial mais geral, propondo que as pessoas que apresentam um comportamento de agressão persistente para com o(a) parceiro(a) amoro- 
so(a), têm grandes probabilidades de ter uma história passada de envolvimento em outros comportamentos antissociais. Além disso, as investigações no domínio da criminologia sustentam que a ausência de práticas parentais efetivas, mais do que a agressão interparental ou mesmo os maus tratos, constitui um importante factor precipitante da violência na intimidade juvenil. Esta leitura estabelece, deste modo, o fenómeno da violência como resultante da ineficácia parental e como tal não nos providencia explicações para os casos de violência em que os seus intervenientes (sejam vítimas ou agressores) são oriundos de famílias sem historial de violência passada.

As perspectivas feministas, pioneiras no reconhecimento das influências culturais na violência íntima, têm igualmente proporcionado contributos importantes nesta matéria, enfatizando o papel das mensagens sociais e culturais na normalização e aprovação da violência na intimidade (cf. Ismail et al., 2007). Segundo estas perspetivas, a violência resulta de um conjunto de valores patriarcais que se foram institucionalizando a vários níveis e sob diferentes formas: ao nível macro-social (e.g., sistema legal, instituições e estruturas sociais), ao nível intergeracional (valores patriarcais transmitidos de geração em geração), ao nível cultural (destacando-se a este nível o papel dos media na reprodução e reforço dos valores patriarcais) e ao nível individual (o indivíduo incorpora os valores patriarcais, reproduzindo-os no seu quotidiano) (Marin \& Russo, 1999).

Desta forma, a variação intercultural que existe na tolerância ao comportamento violento perpetrado sobre a mulher (Nayak, Byrne, Martin, \& Abraham, 2003) está relacionada com a influência dos valores patriarcais em cada cultura (Bui \& Morash, 1999 cit. in Bhanot \& Senn, 2007). Alguns estudos antropológicos (Counts, Brown, \& Campbell, 1999) vão precisamente neste sentido, ao verificar que a violência contra a mulher está relacionada com o valor social que lhe é atribuído e com o seu estatuto social. O poder económico masculino, o isolamento social da mulher, e as normas culturais que valorizam a submissão e a castidade femininas desempenham também um importante papel na promoção da violência.

Não obstante as inúmeras críticas que têm sido dirigidas às perspectivas feministas, não podemos pois negligenciar o importante contributo destas, sobretudo na análise da relação entre género e violência, ao sustentarem que o sistema patriarcal promove as desigualdades de género, tornando possível a emergência de múltiplas e inovadoras práticas interventivas (e.g., desconstrução de estereótipos culturais, constituição de grupos de auto-ajuda, centros de acolhimento para vítimas) (Matos, 2002).

Efetivamente, vários estudos têm vindo a assinalar a importância do género na compreensão da violência, contudo a enorme controvérsia empírica em torno desta relação permite-nos afirmar que o género não explica por si só a violência. 
Ainda que os padrões de vitimação e perpetração neste contexto relacional se apresentem menos diferenciados em termos de género, comparativamente ao que se verifica nas relações maritais, e embora alguns dos nossos resultados empíricos pareçam apoiar a tese da paridade da violência (Machado, Caridade, \& Martins, 2010), a verdade é que esta está longe de ser uma leitura unânime entre os diferentes estudos. Tal como alguns autores defendem (Johnson, 1995), torna-se necessário ponderar a possibilidade de existirem múltiplas formas de violência entre os parceiros íntimos, sendo que algumas destas formas de violência poderão ser simétricas em termos de género e outras não. Nesta lógica de entendimento, a violência íntima não pode pois ser entendida como um fenómeno unitário, antes pelo contrário deverá ser conceptualizada em função da sua multiplicidade.

Atendendo às especificidades de que se reveste a violência na intimidade juvenil, parece-nos fundamental considerar diferentes níveis de compreensão desta realidade, em detrimento de uma análise mais singular. Mais concretamente, consideramos que a centralização num único modelo teórico poderá conduzir a uma visão demasiado redutora na compreensão deste problema, até porque, e tal como a literatura sustenta, vários fatores poderão interferir com o entendimento que vítimas e agressores constroem das experiências violentas.

Face a tudo isto, entendemos que para melhor compreender, prever, e prevenir o abuso nos relacionamentos íntimos juvenis é necessária a adoção de uma abordagem compreensiva, complexa e de carácter multidimensional, seja em termos individuais, interpessoais, estruturais e culturais.

\section{Estado da arte sobre a violência nas relações íntimas juvenis}

$\mathrm{O}$ incremento da investigação e do conhecimento teórico produzido sobre a violência nas relações íntimas juvenis traduz uma maior sensibilização da comunidade científica para a gravidade e dimensão do fenómeno e, consequentemente, uma maior consciencialização social para este problema. A investigação produzida neste domínio, sobretudo no que respeita à realidade internacional, poderá sistematizar-se em torno de três dimensões centrais, as quais se foram desenvolvendo de forma progressiva e pela ordem que apresentamos de seguida:

a) primeiramente, a caraterização da dimensão do fenómeno, procurando-se determinar a prevalência da agressão e vitimação dos diferentes tipos de abuso ocorridos nos relacionamentos íntimos dos jovens. Ainda que se tenha privilegiado o estudo da violência física, registando-se um menor interesse empírico em conhecer a extensão da agressão psicológica, na atualidade, subsiste uma clara preocupação em analisar estas duas formas de 
violência, considerando-se a agressão psicológica como sendo um percursor de outras formas de violência (e.g., Hydén, 1995). Também a agressão sexual tem vindo a suscitar grande atenção por parte da comunidade científica internacional, sobretudo junto dos jovens universitários, contexto onde se tem registado elevados índices de violência sexual no namoro (cf. Martins \& Machado, 2010). Esta preocupação começa a estender-se ao contexto português, sendo possível identificar a existência de alguns estudos específicos neste domínio (e.g., Martins, 2012).

A relação entre vitimação, agressão e género tem sido o domínio de maior atenção, suscitando grande debate e, por vezes, alguma polémica nesta área de investigação. Os primeiros estudos neste domínio, nomeadamente o já referenciado estudo pioneiro nesta área, começou por reportar elevados indicadores de vitimação feminina e elevados indicadores de agressão masculina à semelhança do apurado pelos estudos realizados em outros contextos relacionais (conjugalidade). Assim, Makepeace (1981) apurou que as raparigas tinham mais probabilidades de relatar experiências de vitimação e os rapazes experiências de agressão. Com o progredir da investigação nesta área, outros resultados foram emergindo e, na década de 90, vários estudos concluíram pela existência de níveis similares de vitimação entre rapazes e raparigas (e.g., Follette \& Alexander, 1992; Perry \& Fremouth, 2005; Straus, 2004). Estudos mais recentes desenvolvidos internacionalmente (e.g., Cercone, Beach, \& Árias, 2005; Windle \& Mrug, 2009) e em território português (Caridade, 2011), encontraram resultados mais ambíguos em termos de género, face ao apurado inicialmente, sugerindo-se, por exemplo, que os rapazes poderão experienciar níveis mais elevados de vitimação ou aqueles em que as raparigas admitem mais o recurso à violência.

No mesmo sentido e a título meramente exemplificativo, um estudo muito recente (Jain, Buka, Subramanian, \& Molnar, 2010) apurou que as raparigas $(38 \%)$ reportam mais facilmente o recurso a comportamentos violentos do que os rapazes (19\%). Um estudo intercultural que envolveu 32 países contemplando um total de 13601 participantes, comprovou que o padrão mais comum de violência é bidirecional/recíproca, seguido da violência feminina e depois a violência masculina (Straus, 2008).

b) o estudo dos fatores de risco suscetíveis de incrementar as condutas violentas nas relações de intimidade é igualmente consistente e sólido (e.g., Chase, Freboux, \& O’ Leary, 2002; Glass Fredland, Jacquelyn, Michael, Phyllis, \& Joan, 2003; Gover, 2004; Lewis \& Fremouw, 2001; O’ Keefe, 1998), procurando-se a sua diferenciação em função das características das vítimas e agressores, os quais se podem organizar em seis dimensões centrais: familiares, ambientais, sócio-demográficos, intrapessoais, interpessoais e situacionais (Caridade, 2011). 
c) por fim, a linha de investigação que procura essencialmente promover a conceção e implementação de programas de prevenção primária da violência junto dos jovens (e.g., Hickman et al., 2004). Estes programas têm procurado, essencialmente, promover a consciencialização da população juvenil acerca da gravidade e do impacto da violência e fomentar relacionamentos saudáveis, procurando diminuir a probabilidade dos jovens se tornarem, futuramente, ofensores ou vítimas (Suderman, Jaffe, \& Hastings, 1995). Ainda que haja já alguma preocupação em aferir a eficácia destes programas de prevenção, esta ainda não é uma realidade extensível a todos, nem amplamente praticada, algo que urge corrigir (Caridade, Saavedra, \& Machado, 2012).

No que respeita ao estudo dos efeitos da violência ao nível do ajustamento psicossocial das vítimas mais jovens, a curto e a longo prazo, este é ainda algo incipiente, denotando-se um menor investimento científico neste âmbito. Efetivamente, os múltiplos estudos que procuram analisar as implicações deste tipo de condutas, centraram-se inicialmente na saúde física e psicológica das mulheres adultas agredidas, sendo reduzidos os estudos ao nível das consequências para as vítimas masculinas e juvenis, bem como para os ofensores (Glass et al., 2003).

A ênfase na violência marital e subsequente omissão da violência ocorrida em outros domínios relacionais foi igualmente evidente no contexto científico português. Não obstante este tardio interesse pelo estudo da violência nas relações juvenis de intimidade, é hoje evidente o aumento progressivo e sistemático da investigação neste domínio, sendo possível identificar no nosso país um conjunto de estudos que têm procurado, maioritariamente mediante o recurso a questionários ou inventários, caracterizar a prevalência da violência na intimidade juvenil. Ainda que a grande maioria se centre na população universitária e, portanto, nos jovens adultos, assistimos também à emergência de outros estudos interessados em perceber como esta realidade se manifesta entre os mais novos, recorrendo para isso a amostras de adolescentes ou estudantes do ensino secundário (Machado et al., 2010).

Registamos ainda a emergência de outras linhas de investigação, as quais procuram, mediante o recurso a outro tipo de metodologias (e.g., qualitativas), contribuir para o aumento do conhecimento teórico neste domínio. Destacamos, deste modo, os estudos que procuram analisar como as diferenças e mudanças culturais podem influenciar as taxas e formas de violência na intimidade (Machado \& Dias, 2008) ou, ainda, explorar e compreender a articulação entre os significados culturais do amor e as práticas relacionais violentas, entre as quais, a violência nas relações de intimidade juvenil (Dias, 2012).

Decorrente deste investimento científico, é hoje possível, no plano social e político, identificar a emergência de diversas alterações que refletem 
a maior consciencialização para a gravidade deste fenómeno e a premência na implementação de medidas preventivas do mesmo. Destacam-se, assim, as mais recentes alterações na lei, em que o crime de violência doméstica previsto no artigo $152^{\circ}$ do Código Penal passou a prever a eventual violência entre namorados ${ }^{3}$ e ex-companheiros, sejam casais heterossexuais ou homossexuais. Paralelamente, as entidades públicas (e.g., Comissão para a Cidadania e Igualdade de Género, autarquias, entre outras) ou mesmo as Organizações não Governamentais e/ou Instituições Particulares de Solidariedade Social (e.g., Associação Portuguesa de Apoio à Vítima, União de Mulheres Alternativa Resposta, Associação de Mulheres contra a Violência, e outros projectos comunitários), que outrora privilegiaram o apoio imediato e remediativo, dirigido às mulheres e crianças vítimas de violência doméstica, começam agora, e tendo por base os dados da investigação neste domínio, a desenvolver e implementar esforços preventivos voltados para os grupos mais jovens (cf. Caridade et al., 2012).

O projeto "Violência nas relações juvenis de intimidade", sob a coordenação da segunda autora deste artigo, surge precisamente num período em que se assistia, em Portugal, a um incremento do interesse social e científico para o fenómeno da violência nas relações de intimidade entre os jovens. Este projeto, financiado pela Fundação para a Ciência e Tecnologia (com a duração de quatro anos) surgiu tendo como objetivo reduzir a lacuna existente, na altura da sua conceção, no conhecimento acerca da extensão e gravidade do fenómeno da violência nas relações de intimidade juvenil. Este projeto pretendia assim cumprir quatro grandes propósitos:

i) caraterização da prevalência da violência nas relações juvenis de intimidade;

ii) caraterização das atitudes, crenças e discursos dos jovens sobre a violência;

iii)identificação e avaliação crítica dos programas de prevenção da violência na intimidade juvenil conduzidos em Portugal;

iv) e, ainda, o desenvolvimento, aplicação e avaliação da eficácia de programas de prevenção neste âmbito.

${ }^{3}$ Com a revisão de 2007 , deixou de ser necessária a coabitação, exigindo-se contudo um carácter mais ou menos estável do relacionamento amoroso, aproximando-o ao da relação conjugal. Não obstante, esta questão tem suscitado algum debate entre os juristas, não se observando consenso acerca da aplicabilidade deste tipo legal às situações de maus tratos ocorridas nas relações de namoro. Na generalidade, tem-se defendido que só em casos muito pontuais (e em que há fortes indícios de ocorrência criminal e da existência de uma relação amorosa) se procede à aplicação deste tipo legal de crime a este contexto relacional - namoro. 
De seguida e de forma muito sucinta ${ }^{4}$, procuraremos apresentar alguns dos principais resultados obtidos pelos diferentes estudos desenvolvidos no âmbito deste projeto de investigação e os quais deram origem a várias publicações internacionais, nacionais, e ainda, teses de mestrado e doutoramento.

Ainda que na altura da implementação deste projeto existissem já alguns estudos sobre a prevalência da violência nas relações de intimidade juvenis (Lucas, 2005; Paiva \& Figueiredo, 2004), o estudo iniciado pela primeira autora deste trabalho em 2004, no âmbito da sua tese de doutoramento, foi o primeiro a recorrer a uma amostra alargada (recolhendo-se dados em diferentes áreas geográficas: desde a zona norte, centro, sul, incluindo também as ilhas, Açores e Madeira) e que procurou envolver jovens de diferentes níveis de ensino. A amostra final deste estudo integrou 4667 jovens com idades compreendidas entre os 13 e os 29 anos, distribuídos pelo ensino secundário, profissional ou universitário (Machado et al., 2010).

Neste estudo, e tomando o conjunto de participantes envolvidos em relacionamentos íntimos juvenis, apurou-se que $25,4 \%$ dos jovens relataram ter sido vítimas de pelo menos um acto abusivo durante o ano anterior ao estudo e 30,6\% assumiram adotar comportamentos violentos face ao seu parceiro atual (Machado et al., 2010).

Ainda no mesmo estudo, foram avaliados os diferentes tipos de violência praticados e sofridos pelos jovens nos seus relacionamentos íntimos atuais, sendo que 19,5\% relataram ter sofrido algum tipo de violência emocional, $13,4 \%$ de violência física e $6,7 \%$ relataram sofrer violência física severa; por outro lado, 22,4\% admitiram ter exercido violência emocional sobre os seus parceiros, $18,1 \%$ perpetraram violência física e 7,3\% admitiram recorrer à violência física severa. Constatou-se que, apesar do nível socioeconómico dos jovens não influenciar os seus comportamentos de vitimação e perpetração, o mesmo não se verificava quando se analisou o efeito das variáveis género, idade e escolaridade. De forma mais específica, as raparigas admitiram níveis mais elevados de agressão global, física e emocional, admitindo sofrer, por outro lado, maior vitimação física. Foram os grupos etários mais velhos e que frequentavam o ensino superior aqueles que mais relataram ter recorrido e terem sido alvo de violência global e emocional, enquanto os jovens do ensino profissional relataram sobretudo a agressões físicas e vitimação ao nível físico e físico severo (Machado et al., 2010).

\footnotetext{
${ }^{4} \mathrm{Na}$ medida em que alguns dos estudos desenvolvidos no âmbito deste projeto estão também publicados nesta revista, neste número, remeteremos para a leitura integral dos artigos, sempre que nos referirmos a estes ao longo deste texto.
} 
Uma vez que este primeiro estudo de prevalência deu particular ênfase à violência física e emocional, avaliando a violência sexual de forma muito superficial (apenas inquirida num item do instrumento usado ${ }^{5}$ ) e dado que se pretendia aprofundar o conhecimento neste domínio, foi projetado um outro estudo de prevalência centrado nesta forma de violência específica e realizado com uma amostra representativa de estudantes universitários (Martins \& Machado, em preparação).

Um segundo grande objetivo do projeto era investigar as atitudes dos jovens acerca da violência nos relacionamentos íntimos juvenis, algo que foi igualmente atendido pelos dois estudos de prevalência já referidos. De uma forma geral, ambos os estudos (Machado et al., 2010; Martins \& Machado, em preparação) apuraram uma tendência geral dos jovens para a reprovação da violência física, emocional e sexual em contextos de intimidade.

Não obstante, e no que diz respeito à violência física e emocional, verificou-se uma maior tolerância por parte dos elementos de sexo masculino, de faixas etárias mais jovens, com menor escolaridade, de níveis socioeconómicos mais desfavorecidos e com menos experiências relacionais (Machado et al., 2010).

Ao nível das atitudes acerca da violência sexual verificou-se um padrão semelhante, com os jovens de sexo masculino e com menor escolaridade a evidenciarem uma maior legitimação dos comportamentos sexualmente abusivos (Martins \& Machado, em preparação).

De forma a aprofundar as significações dos jovens acerca da violência em relações de intimidade juvenil, e também na expectativa de clarificar a contradição verificada entre comportamentos e atitudes registada nos dois estudos de prevalência já referenciados, realizaram-se ainda alguns estudos de carácter qualitativo no âmbito do projeto que temos vindo a descrever, quer através de focus-group (Caridade, 2011), quer de entrevistas individuais (Dias, Manita, \& Machado, publicado nesta revista).

Assim, foram realizados nove focus-group com jovens, três em cada nível de formação em análise (ensino secundário, profissional e superior). Em cada nível de ensino, um grupo era exclusivamente masculino, outro exclusivamente feminino e o outro misto. Em termos gerais, os discursos dos jovens revelaram-se congruentes com as suas atitudes, exprimindo a condenação dos diferentes tipos de violência e considerando esta problemática relevante na medida em que os comportamentos violentos na intimidade juvenil são avaliados como comuns e precursores da violência em relações de intimidade futuras (Caridade, 2011). No entanto, uma análise mais detalhada concluiu pela existência de discrepâncias entre esta posição geral e a aceitação da violência e sua desculpabilização em certos contextos específi-

\footnotetext{
${ }^{5}$ Inventário de violência conjugal (Matos, Machado, \& Gonçalves, 2008).
} 
cos. Mais concretamente, verificou-se uma tendência para a avaliação da violência sexual como rara e para a banalização da violência emocional e de alguns atos de violência sexual entendidos como menos graves. Acresce que a conceptualização que os jovens atribuem ao abuso surge como sendo dependente da intenção do agressor, do contexto da agressão e do impacto causado, procedendo-se a uma maior desculpabilização do comportamento violento quando aquele é atribuído à impulsividade e descontrolo do agressor, quando este manifesta arrependimento, quando o abuso não ocorre em público e quando daí não decorrem consequências físicas graves (Caridade, 2011).

Apesar dos jovens reconhecerem a existência de padrões de poder diferenciados em função do género, associados à violência, tendem a enfatizar fatores familiares, do grupo e do meio (e.g., experienciação e/ou exposição à violência na família, influência do grupo de amigos), e características intrapessoais (e.g., impulsividade, falta de auto-controlo, consumo de substâncias) como causas da violência, prevalecendo também discursos culpabilizadores da vítima em função da sua tolerância à violência ou da precipitação da mesma através de comportamentos atuais e/ou prévios (e.g., vestuário, infidelidade).

Considerando a possibilidade dos discursos juvenis sobre a violência na intimidade estarem enquadrados em discursos mais abrangentes sobre o amor, Dias procedeu a uma análise comparativa entre o discurso dos sujeitos com história de violência nas relações de intimidade e o discurso dos sujeitos sem história de violência, tanto na população juvenil como na população adulta, tendo emergido repertórios interpretativos para o amor tipificados pela autora em: "amor romântico", "amor apaixonado", "amor companheiro" e "amor desencantado" (Dias, Manita, \& Machado, em preparação).

Da realização de todos estes estudos, de índole qualitativa e quantitativa, emergiu a constatação de números significativos de violência na intimidade juvenil, aliados à persistência de significações e crenças que perpetuam a genderização do poder e legitimam a violência. Reforça-se, desta forma, a necessidade de desenvolver e avaliar programas de prevenção nesta área, para o que é fundamental conhecer e avaliar os esforços desenvolvidos até ao momento no nosso país (Saavedra \& Machado, no prelo).

A partir de uma revisão sistemática da literatura internacional acerca dos programas de prevenção primária da violência nos relacionamentos íntimos juvenis, foi possível constatar que os programas mais longos e mais focalizados no treino de competências apresentam resultados mais promissores (Saavedra \& Machado, no prelo). No mesmo sentido, partindo de um inquérito (Saavedra \& Machado, no prelo) efetuado junto de entidades nacionais especializadas no campo da violência doméstica, sobre as suas ações de prevenção primária levadas a cabo, concluiu-se que os esforços de prevenção desenvolvidos em Portugal se afiguram, até ao momento de reali- 
zação deste estudo, deveras reduzidos, breves e, maioritariamente, adotando uma lógica informativa e educacional (ibidem).

Findo este trabalho de análise e caracterização da cultura de prevenção nesta área, quer no contexto internacional, quer nacional, procedeu-se ainda à implementação em Portugal do The Fourth $R$ - um currículo de prevenção universal que se destina a prevenir a violência no namoro e os comportamentos de risco associados (Saavedra, Martins \& Machado, publicado nesta revista).

Por último e uma vez constatado o papel determinante que os pares desempenham na vida dos jovens, sendo pelos próprios (sobretudo pelos rapazes) percebidos como potenciais modelos e fontes de reforço da violência e fontes de eleição dos jovens para partilharem as suas experiências abusivas amorosas (Caridade, 2011), procurou-se ainda delinear um programa de prevenção por pares (Coelho \& Machado, em preparação).

Após a conclusão deste projeto de investigação, e uma vez observadas as similaridades entre a violência ocorrida nas relações íntimas juvenis e a violência ocorrida nas relações maritais, como o referenciado anteriormente, procedemos ainda à realização de um estudo comparativo (Machado, Martins, \& Caridade, 2012). Tendo por base duas amostras de participantes distintas - jovens envolvidos em relações de namoro e adultos envolvidos em relações maritais, - pretendia-se: i) analisar e comparar as atitudes dos participantes envolvidos em relações de namoro e relações maritais; ii) analisar e contrastar a prevalência da violência perpetrada e sofrida, nas duas amostras; iii) investigar as diferenças de género em termos de vitimação e perpetração, atendendo ao tipo de contexto relacional. Para tal, participaram no estudo um total de 3.716 participantes, com idades compreendidas entre os 15 e os 67 anos, e os quais responderam a dois questionários: um de atitudes e outro de comportamentos. Em termos atitudinais, e pese embora a tendência geral dos participantes para a reprovação da violência, os participantes de sexo masculino e o grupo dos casados surgiram como sendo os mais legitimadores da violência. Quando comparamos a violência ocorrida nos dois contextos relacionais, e no que respeita ao padrão de agressão, os participantes envolvidos em relações de namoro assumiram, comparativamente com os casados, o maior recurso à violência física $(16,4 \%$ e $12,8 \%$ respetivamente) e física severa $(8 \%$ e $4,7 \%$, respetivamente). Em contrapartida, os participantes casados assumiram recorrer mais frequentemente aos comportamentos emocionalmente abusivos ( $26 \%$ contra $21 \%$ registados no namoro). De igual modo, a vitimação das diferentes formas de violência estudadas é assumida mais frequentemente pelos casados, especialmente a vitimação emocional. Para ambos os contextos relacionais, foram detetadas diferenças de género, em termos de vitimação e agressão: nas relações de namoro, os rapazes admitiram o maior recurso à violência física severa $(11,9 \%$ contra $5,6 \%$ 
registado pelas raparigas) e as raparigas assumem-se como sendo as principais vítimas deste tipo de violência $(9,5 \%$ contra $6,2 \%$ registado nos rapazes). Para as outras formas de violência estudadas neste contexto relacional (global, emocional e física) não se verificaram diferenças de género. Nas relações maritais, e no que ao padrão de agressão diz respeito, registou-se grande paridade de género para as diferentes formas de violência estudadas (a agressão global foi admitida por $31,8 \%$ dos homens e $28,7 \%$ das mulheres; a violência física por $13,6 \%$ dos homens e $12,1 \%$ das mulheres; a violência emocional por $27,4 \%$ dos homens e $24,8 \%$ das mulheres), algo que poderá eventualmente dever-se às características da amostra (população normativa). Já no que respeita à vitimação, as mulheres, comparativamente com os homens, surgem como sendo as mais vitimadas pela violência em termos gerais (33,7\% vs. $27,3 \%$ registados, respetivamente), física (16\% vs. $9,7 \%$, respetivamente), física severa ( $12 \%$ vs. $3,3 \%$, respetivamente), e emocional (30,2\% vs. 24,7\%, respetivamente) (Machado et al., 2012).

\section{Conclusão: Novos desafios para a investigação e intervenção}

A análise da literatura permite-nos, assim, concluir que a violência nas relações de intimidade não é uma experiência incomum entre os jovens, sendo na atualidade amplamente reconhecida como uma problemática de dimensões preocupantes e efeitos alarmantes, não somente a nível individual mas em toda a esfera social. Os estudos empíricos que desenvolvemos neste domínio, e que corroboram os dados da investigação internacional, demonstram que as faixas etárias mais jovens não estão imunes a este problema, sugerindo, quer a existência de indicadores significativos de vitimação e agressão, quer a manutenção de discursos legitimadores deste tipo de violência.

Face a estas evidências e não obstante o já documentado progresso em termos de investigação neste domínio, parece-nos fundamental que se continue a apostar no desenvolvimento de estudos que possibilitem expandir a nossa compreensão do problema em causa, razão pela qual passamos a sugerir algumas pistas e/ou desafios para a investigação futura nesta área.

Desde logo, no plano da prevalência do fenómeno, destacamos a necessidade de garantir a possibilidade de generalização dos dados à população juvenil portuguesa, com uma distribuição mais equitativa dos participantes entre as diferentes regiões, de diferentes contextos formativos, incluindo-se igualmente jovens fora do sistema de ensino.

Atendendo à existência de evidências que comprovam que a violência nas relações íntimas juvenis constitui um preditor da violência marital e que o padrão de violência marital poderá estabilizar-se durante o período do namoro (e.g., Frieze \& Brown, 1989), parece-nos ser também de grande 
interesse o desenvolvimento de estudos longitudinais que procurem comparar padrões evolutivos de violência no sentido de melhor clarificar estas questões.

Um dos dados mais interessantes da investigação sobre a violência nas relações de intimidade juvenis reside na contradição entre a elevada prevalência das condutas abusivas adotadas pelos jovens e a aparentemente reduzida aceitação social da violência. Os resultados obtidos no âmbito deste projeto de investigação comprovam isto mesmo: ainda que os jovens, genericamente, afirmem reprovar a violência, registam-se taxas de prevalência claramente superiores às dos casais adultos, algo que é de facto preocupante. Parece subsistir, assim, uma discrepância entre aquilo que são as práticas/comportamentos e as crenças/atitudes dos jovens. A exploração desta questão, mediante a realização de grupos de discussão, confirma esta tendência dos jovens para contestarem a violência, num plano mais global. Sobressai, contudo, uma tendência para os jovens identificarem situações de exceção em que a violência é considerada legítima (e.g., quando ocorre em privado; de forma impulsiva; quando assume menor gravidade; quando é percebida como decorrente da psicopatologia do agressor ou quando seguida de desculpas) (Caridade, 2011). É uma realidade que os esforços de prevenção se têm multiplicado, promovendo uma maior consciencialização dos jovens para estas dinâmicas e para a contestação social desta realidade. Parece subsistir, contudo, um problema da excecionalidade - "Ok, a violência é errada mas... em certas situações é aceitável, legítima" (Machado, 2010, pág. 4), fundamentando-se, deste modo, a necessidade em clarificar esta incongruência detetada entre atitudes e comportamentos, nomeadamente, o entendimento dos mecanismos cognitivos e emocionais utilizados para justificar a violência.

A investigação científica nacional nesta área tem privilegiado o recurso ao auto-relato dos inquiridos, pelo que consideramos ser de extrema relevância a utilização de outros métodos de recolha de informação (e.g., entrevistas individuais aprofundadas, entrevistas com pares de namorados, grupos de discussão, exposição a situações de conflito relacional seguido de role play) e que possam proporcionar um conhecimento mais aprofundado desta realidade. Tal sugestão prende-se, essencialmente, com o facto da violência nas relações íntimas juvenis constituir uma experiência pessoal, privada, e frequentemente acompanhada por sentimentos de culpa, o que, não raras vezes, condiciona os relatos dos inquiridos, promovendo o sub-relato deste tipo de experiências.

Assim, no plano qualitativo, parece-nos fundamental a análise das experiências diretas dos jovens com a violência íntima, quer enquanto vítimas, quer como agressores. A realização de entrevistas individuais aprofundadas com jovens com estas experiências permitir-nos-ia, é nossa convicção, 
avançar também e de forma significativa na compreensão das contradições verificadas entre atitudes e comportamentos, como já referenciado. Do mesmo, consideramos que a realização destas entrevistas individuais poderão fornecer mais elementos para a compreensão da relação entre género e violência, por exemplo, elucidando os contextos e motivações da violência feminina.

Quer para aprofundar a questão do género, quer para melhor compreender a violência juvenil em termos gerais, importa também conhecer os contextos em que a violência é praticada por cada um dos parceiros (e.g., auto-defesa, controlo do parceiro amoroso, expressão de raiva), a influência do consumo de álcool nos comportamentos violentos (ao nível da vitimação e perpetração), as reações da vítima às agressões e o impacto da violência (no relacionamento amoroso e nos agentes envolvidos). De igual modo, urge compreender se e a quem os jovens relatam estas situações, em que circunstâncias o fazem e o que os demove de as denunciar.

Importa ainda perceber como a dimensão cultural poderá influenciar a construção social do género e dos relacionamentos violentos. Neste âmbito, alguns autores alertam para a necessidade de se apostar na investigação cultural sobre a violência e o amor, mediante a análise aprofundada dos discursos dos jovens, quer os que estejam envolvidos em relações violentas, quer jovens isentos de experiências abusivas, procedendo-se à sua contrastação. Defendem, deste modo, a necessidade de se identificar e analisar os discursos que podem limitar e/ou promover relacionamentos saudáveis (Dias, 2012).

Atendendo a que investigação nesta área se centra, maioritariamente, nos jovens individualmente considerados, seria igualmente importante que os estudos procurassem contemplar nas suas amostras pares de namorados, o que nos iria permitir, por um lado, obter estimativas mais precisas sobre a frequência da violência, dado que há estudos que comprovam que os sujeitos individuais tendem a subestimar a frequência da violência e, por outro lado, iria permitir reduzir as discrepâncias entre os dados obtidos entre casais e indivíduos. Tal é particularmente pertinente se considerarmos que os parceiros amorosos, regra geral, tendem a definir e a interpretar os comportamentos amorosos de forma distinta e, como tal, analisar os relatos de um só membro da relação não permite aceder às perceções e atitudes do outro membro.

Uma outra tendência registada na investigação neste domínio relaciona-se com o facto de se incluírem nos estudos apenas relações formais e casais heterossexuais, descurando-se outro tipo de vínculos relacionais não formais (casos de divórcio, separação) ou mesmo as relações homossexuais. A título exemplificativo, Brown e Bulanda (2008) defendem que as relações de coabitação, mas em que não há formalização do vínculo relacional (uniões de facto), se afiguram mais violentas comparativamente com as rela- 
ções maritais, existindo uma maior probabilidade de as mulheres reagirem violentamente contra os seus parceiros e de serem mais vitimadas por estes. Atendendo a que a violência nas relações de intimidade se afigura como um fenómeno transversal a diferentes contextos relacionais (namoro, casamento, coabitação), justifica-se a necessidade da investigação se estender a outros contextos relacionais, no sentido de promover o desenvolvimento e implementação de programas mais adequados às diferentes realidades.

Por último, não será também de negligenciar o papel preponderante que os mass media ocupam na vida dos jovens, seja através da televisão, filmes, revistas, jogos de vídeo, internet e respetivas redes sociais, pelo que importa igualmente perceber que influência poderão ter no recurso à violência nas relações íntimas juvenis, à semelhança do que já existe para outros comportamentos de risco adotados pelos jovens (e.g., consumo de substâncias, comportamentos sexuais de risco) (Manganello, 2008). Tal é particularmente pertinente porque quando os jovens são inquiridos acerca das causas para a violência nas relações íntimas, reconhecem a influência dos media (pornografia, filmes) como sendo um factor precipitante de determinadas atitudes, conhecimentos e comportamentos (Lavoie, Robitaille, \& Hebert, 2000).

Em matéria de prevenção neste domínio, parece-nos fundamental sublinhar que ainda que as lógicas de sensibilização para o problema se afigurem importantes e fundamentais, são claramente insuficientes para combater este fenómeno de grande complexidade social. Urge, portanto, a necessidade de os esforços de prevenção progredirem para intervenções mais prolongadas no tempo (Caridade et al., 2012).

O papel primordial da escola no desenvolvimento dos jovens, na promoção de múltiplas aprendizagens, na formação das primeiras relações de intimidade, mas também na disseminação de determinadas condutas violentas, converte-a num espaço privilegiado de ação junto dos jovens e, indiretamente, junto de diversos elementos da comunidade, tornando os esforços preventivos mais abrangentes e articulados. Neste sentido, consideramos, pois, a necessidade de perceber os jovens não como meros alvos de intervenção passivos, mas como potenciais agentes ativos de mudança, capazes de interiorizar nova informação e desconstruir mitos, de adquirir competências e utilizá-las adequadamente, e de refletir sobre os efeitos benéficos ou prejudiciais dos seus comportamentos, tomando assim decisões responsáveis com repercussões em todo o seu mundo relacional. 


\section{Referências}

Aldrighi, T. (2004). Prevalência e cronicidade da violência física no namoro entre jovens universitários do estado de São Paulo - Brasil. Psicologia: Teoria e Prática, 6, 105-120.

Bhanot, S., \& Senn, Y. (2007). Attitudes towards violence against women in men of south Asian ancestry: are acculturation and gender role attitudes important factors? Journal of Family Violence, 22, 25-31.

Brown, S. L., \& Bulanda, J. R. (2008). Relationships violence in young adulthood: a comparison of daters, cohabitors, and marrieds. Social Science Research, 37, 73-87.

Caridade, S. (2011). Vivências intimas violentas. Uma abordagem cientifica. Coimbra: Almedina.

Caridade, S., Saavedra, R., \& Machado, C. (2012). Práticas de prevenção da violência nas relações de intimidade juvenil: orientações gerais. Análise Psicológica, $X X X, 131-142$.

Cercone, J. J., Beach, S. R. H., \& Arias, I. (2005). Gender symmetry in dating intimate partner violence: does similar behaviour imply similar constructs? Violence and Victims, 20, 207-218.

Chase, K. A., Treboux, D., \& O'Leary, K. D. (2002). Characteristics of high-risk adolescent's dating violence. Journal of Interpersonal Violence, 17, 33-49.

Coelho, C., \& Machado, C. (publicado nesta revista). Prevenção da violência entre jovens através da educação por pares: Apresentação de um programa piloto. Psicologia.

Counts, D., Brown, J., \& Campbell, J. (1999) (Eds.). To have and to hit. Cultural perspectives on wife beating. Urbana: University of Illinois Press.

Dias, A. R. (2012). Repertórios interpretativos sobre o amor: das narrativas culturais às conjugalidades violentas. Dissertação de candidatura ao grau de Doutoramento. Braga: Escola de Psicologia. Universidade do Minho.

Dias, A. R. \& Manita, C. \& Machado, C. (publicado nesta revista). Relações de intimidade juvenis e adultas, uma análise comparativa: das narrativas de amor às conjugalidades violentas. Psicologia.

Dutton, D. (1999). Limitations of social learning models in explaining intimate aggression. In X. B. Arriaga \& S. Oskamp (Eds.). Violence in intimate relationships (pp. 73-87). California: Sage.

Follette, V. M., \& Alexander, P. C. (1992). Dating violence: current and historical correlates. Behavioral Assessment, 14, 39-52.

Follingstad, D. R., Bradley, R. G., Laughlin, J. E., \& Burke, L. (1999). Risk factors and correlates of dating violence: The relevance of examining frequency and severity levels in a college sample. Violence and Victims, 14, 365-379.

Foo, L., \& Margolin, G. (1995). A multivariate investigation of dating aggression. Journal Family Violence, 10, 351-377. 
Foshee, V. A., Bauman, K. E., \& Linder, G. F. (1999). Family violence and the perpetration of adolescent dating violence: examining social learning and social control processes. Journal of Marriage and the Family, 61, 331-342.

Gelles, R.J. (1997). Intimate violence in families. Thousand Oaks: Sage Publications.

Glass, N., Fredland, N., Jacquelyn, C., Michael, Y., Phyllis, S., \& Joan, K. (2003). Adolescent dating violence: prevalence, risk factors, health outcomes, and implications for clinical practice. JOGNN Clinical Issues, 32, 227-238.

Gover, A. R. (2004). Risk lifestyles and dating violence: a theoretical test of violent victimization. Journal of Criminal Justice, 32, 171-180.

Henton, J., Cate, R., Koval, J., Lloyd, S., \& Christopher, S. (1983). Romance and violence in dating relationships. Journal of Family Issues, 4, 467-482.

Hickman, L. J., Jaycox, L. H., \& Aronoff, J. (2004). Dating violence among adolescents: prevalence, gender distribution and prevention program effectiveness. Trauma, Violence \& Abuse, 5, 123-142.

Hines, D. A., \& Saudino, K. J. (2002). Intergenerational transmission of intimate partner violence. A behavioural genetic perspective. Trauma, Violence \& Abuse, 3, 210-225.

Hydén, M. (1995). Verbal aggression as a prehistory of woman battering. Journal of Family Violence, 10, 55-71.

Ismail, F., Berman, H., \& Ward-Griffin, C. (2007). Dating violence and the health of young women: a feminist narrative study. Health Care for Women International, 28, 453-477.

Jackson, S. M. (1999). Issues in the dating violence research: a review of the literature. Aggression and Violent Behavior, 4, 233-247.

Jain, S., Buka, S. L., Subramanian, S. V., \& Molnar, B. E. (2010). Neighborhood predictors of dating violence victimization and perpetration in young adulthood: a multilevel study. American Journal of Public Health, 9, 1737-1744.

Johnson, K. K. P. (1995). Attributions about date rape: impact of clothing, sex, money spent, date type, and perceived similarity. Family and Consumer Sciences Research Journal, 23, 292-310.

Lavoie, F., Robitaille, L., \& Hébert, M. (2000). Teen dating relationships aggression. An exploratory study. Violence Against Women, 6, 6-36.

Lewis, S. F., \& Fremouw, W. (2001). Dating violence: A critical review of the literature. Clinical Psychology Review, 21, 105-127.

Lichter, E. K., \& McCloskey, L. A. (2004). The effects of childhood exposure to marital violence on adolescent gender-role beliefs and dating violence. Psychology of Women Quarterly, 28, 344-357.

Lucas, S. C. (2002). A agressividade no namoro de adolescentes. Dissertação do II curso de mestrado na especialidade de sexologia. Lisboa: Universidade Lusófona de Humanidades e Tecnologias.

Luthra, R. \& Gidycz, C. A. (2006). Dating violence among college men and women: evaluation of a theoretical model. Journal of Interpersonal Violence, 21, 717-731 . 
Machado, C., Caridade, S., \& Martins, C. (2010). Violence in juvenile dating relationships: Self-reported prevalence and attitudes in a Portuguese sample. Journal of Family Violence, 25, 43-52.

Machado, C., Martins, C., \& Caridade, S. (submetido para publicação). Violence in intimate relationships: A comparison of married and dating couples. Journal of Interpersonal Violence.

Machado, C. (2010). Violências e Vitimização. Entrevista 50 minutos. Lisboa: Sociedade Portuguesa de Psicoterapias Construtivistas.

Machado, C., \& Dias, A. R. (2008). Cultura e violência familiar. Uma revisão crítica da literatura. Revista Brasileira de Informação Bibliográfica em Ciências Sociais, 64, 43-74.

Mahlstedt, D., \& Welsh, L. A. (2005). Perceived causes of physical assault in heterosexual dating relationships. Violence Against Women, 11, 447-472.

Makepeace, J. M. (1981). Courtship violence among college students. Family Relations, 30, 97-102.

Manganello, J. A. (2008). Teens, dating violence, and media use. A review of literature and conceptual model for future research. Trauma, Violence, \& Abuse, 9, 3-18.

Marin, A. J., \& Russo, N. F. (1999). Feminist perspectives on male violence against women: Critiquing O’Neil and Harway's Model. In Harway, M. \& O’Neil, J. (Eds), What causes men's violence against women? Thousands Oaks: Sage.

Martins, S. (2012). Vitimização e perpetração sexual em jovens adultos: da caracterização da prevalência as atitudes. Dissertação de candidatura ao grau de Doutoramento. Braga: Escola de Psicologia. Universidade do Minho.

Martins, S., \& Machado, C. (2010). Violência sexual em jovens adultos: caraterização e implicações para a investigação. In C. Machado (coord.). Novas formas de vitimação criminal (pp. 61-120). Braga: Psiquílibrios.

Martins, S. \& Machado, C. (em preparação). Comportamentos e atitudes face à violência sexual nas relações de intimidade.

Matos, M. (2002). Violência conjugal. In C. Machado, \& R. A. Gonçalves (Coords.), Violencia e vítimas de crimes. Vol I: Adultos (pp. 81-130). Coimbra: Quarteto.

Machado, C., Matos, M., \& Gonçalves, M. (2008). Manual da Escala de Crenças sobre Violência Conjugal (E.C.V.C.) e do Inventário de Violência Conjugal (I.V.C.). Braga: Psiquilibrios Edições.

Miller, L. (2011). Physical abuse in a college setting: a study of perceptions and participation in abusive dating relationships. Journal of Family Violence, 26, 71-80.

Nayak, M. B., Byrne, C. A., Martin, M. K., \& Abraham, A. G. (2003). Attitudes toward violence against women: a cross-nation study. Sex Roles, 49, 333-342.

O'Keefe, M. (1998). Factors mediating the link between witnessing interparental violence and dating violence. Journal of Family Violence, 13, 39-57.

Paiva, C., \& Figueiredo, B. (2004). Abuso no relacionamento íntimo: Estudo de prevalência em jovens adultos portugueses. Psychologica, 36, 75-107. 
Perry, A. R., \& Fromuth, M, E. (2005). Courtship violence using couple data. Characteristics and perceptions. Journal of Interpersonal Violence, 20, 1078-1095.

Riggs, D. S., \& O’Leary, K. D. (1996). Aggression between heterosexual dating partners. An examination of a causal model of courtship aggression. Journal of Interpersonal Violence, 11, 519-540.

Saavedra, R., \& Machado, C. (no prelo). Programas de prevenção primária da violência nos relacionamentos íntimos: uma revisão sistemática da prática internacional e portuguesa. Revista de Psicologia da Criança e do Adolescente.

Saavedra, R., \& Machado, C. (publicado nesta revista). Violência nas relações de namoro entre adolescentes: Avaliação do impacto de um programa de sensibilização e informação em contexto escolar. Revista Psicologia.

Sharpe, D., \& Taylor, J. K. (1999). An examination of variables from a social-developmental model to explain physical and psychological dating violence. Canadian Journal of Behavioural Science, 31, 165-175.

Simons, R. L., Lin, K-H., \& Gordon, L. C. (1998). Socialization in the family of origin and male dating violence: a prospective study. Journal of Marriage and the Family, 60, 467-478.

Straus, M. A. (2004). Prevalence of violence against dating partners by males and female university students worldwide. Violence Against Women, 10, 790-811.

Straus, M. A. (2008). Dominance and symmetry in partner violence by male and female university students in 32 nations. Children and Youth Services Review, 30, 252-275.

Sudermann, M., Jaffe, P., \& Hastings, E. (1995). Violence prevention programs in secondary (high) schools. In Jaffe, P. \& Edleson. J. (Editors) Ending the cycle of violence. Community responses to children of battered women ( $\mathrm{pp} 232-254)$. Thousand Oaks, CA: Sage.

Sugarman, D. B., \& Hotaling, G. T. (1989). Dating violence: Prevalence, context, and risk markers. In M. A. Pirog-Good \& J. E. Stets (Eds), Violence in dating relationships. Emerging social issues (pp. 3-32). New York: Praeger Published.

Windle, M., \& Mrug, S. (2009). Cross-gender violence perpetration and victimization among early adolescents and associations with atitudes toward dating conflict. Youth Adolescence, 38, 429-439. 